\title{
REVIEW
}

\section{The state of gene therapy research in Africa, its significance and implications for the future}

\author{
P Arbuthnot ${ }^{1}$, MB Maepa ${ }^{1}$, A Ely ${ }^{1}$ and MS Pepper ${ }^{2}$
}

Gene therapy has made impressive recent progress and has potential for treating a wide range of diseases, many of which are important to Africa. However, as a result of lack of direct public funding and skilled personnel, direct research on gene therapy in Africa is currently limited and resources to support the endeavor are modest. A strength of the technology is that it is based on principles of rational design, and the tools of gene therapy are now highly versatile. For example gene silencing and gene editing may be used to disable viral genes for therapeutic purposes. Gene therapy may thus lead to cure from infections with HIV-1, hepatitis B virus and Ebola virus, which are of significant public health importance in Africa. Although enthusiasm for gene therapy is justified, significant challenges to implementing the technology remain. These include ensuring efficient delivery of therapeutic nucleic acids to target cells, limiting unintended effects, cost and complexity of treatment regimens. In addition, implementation of effective legislation that will govern gene therapy research will be a challenge. Nevertheless, it is an exciting prospect that gene therapy should soon reach the mainstream of medical management. Participation of African researchers in the exciting developments is currently limited, but their involvement is important to address health problems, develop capacity and enhance economic progress of the continent.

Gene Therapy (2017) 24, 581-589; doi:10.1038/gt.2017.57

\section{INTRODUCTION}

The term 'Gene Therapy' was originally coined in 1972 to describe an approach to disease treatment that involved genetic modification of cells. ${ }^{1}$ Initial research in the field focused on introduction of genes into cells to achieve a therapeutic effect. However, the scope of gene therapy has since expanded to include use of any nucleic acid to alter gene function (reviewed in Collins et al. ${ }^{2}$ Naldini ${ }^{3}$ ). Since the way in which genes function underlies normal and pathological processes, employing technology that specifically modifies gene function has utility for treating a variety of diseases. Many conditions that are of serious public health importance in Africa are thus amenable to treatment using gene therapy. The technology is therefore of significance to the management of disease on the continent. Despite its potential importance, direct research on the topic in Africa has been limited. Although Africa has good research-intensive institutions, the continent loses most of its skilled personnel to laboratories in North America, Europe and Australasia. ${ }^{4}$ Consequently there is a scarcity of capable molecular biologists to carry out research on gene therapy. To strengthen human resource capacity, a priority is to create platforms that will attract qualified scientists and incentivize trained African scientists to remain on the continent. To date investigations have largely involved advancing therapeutic nucleic acids for management of hepatitis $B$ virus (HBV $)^{5-8}$ and HIV-1 infections. ${ }^{9,10}$

A particularly powerful feature of gene therapy is that design of candidate drugs is based on rational design that is essentially based on information about nucleic acid sequences. ${ }^{2,3}$ Recent impressive progress of sequencing technology, coupled with advances in broader fields of molecular biology, virology, oncology and synthetic chemistry, amongst others, have provided valuable resources for advancing gene therapies. Design of novel gene therapies is becoming more reliable and improved insights are leading to use of efficient standardization of drug development protocols. Although versatile, strategies employing gene therapy to treat disease require complex, labor intensive and time consuming multi-step processes. These are expensive and implementation requires sophisticated infrastructure to comply with regulatory requirements (Table 1 ). During preclinical development, specialized skills and equipment are required for gene therapeutics design and production. Large scale production of gene therapeutics before clinical testing requires facilities that meet the requirements for good manufacturing practice, which are lacking in Africa. ${ }^{11}$ These are important factors to be taken into account when considering feasibility of gene therapy in resourcepoor settings of Africa.

Many different expressed or synthetic nucleic acids, as well as their chemically modified derivatives, are now considered to be gene therapeutics. Concommitant with the broader range of gene therapy-active molecules, the diseases that are now considered to be feasible therapeutic targets are highly varied. Treatment of viral infections, cancers, inherited diseases and immunotherapy are now all within the realm of gene therapy. ${ }^{2,3}$ The technology is, however, not yet widely used in clinical settings, and licenses have usually only been granted in particular countries. Examples of gene therapies are Spinraza for treatment of spinal muscular

\footnotetext{
${ }^{1}$ Wits/SAMRC Antiviral Gene Therapy Research Unit, Department of Molecular Medicine and Haematology, School of Pathology, Faculty of Health Sciences, University of the

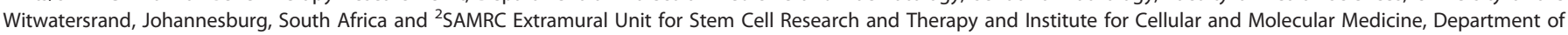

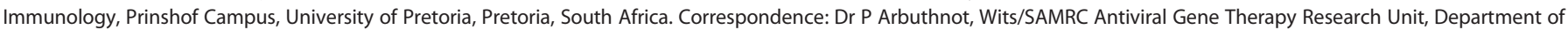
Molecular Medicine and Haematology, School of Pathology, Faculty of Health Sciences, University of the Witwatersrand, 7 York Road, Parktown, Johannesburg, Gauteng 2193, South Africa.
} 
Table 1. Infrastructure requirements for development of gene therapy candidates, with capabilities and limitations in Africa

\begin{tabular}{|c|c|}
\hline Infrastructure requirements & Capabilities/limitations in Africa \\
\hline \multicolumn{2}{|l|}{ Preclinical development of gene therapy } \\
\hline 1. Expert human resources & $\begin{array}{l}\text { Few specialists in gene therapy. Molecular biology capabilities adequate but not uniform } \\
\text { over the continent }\end{array}$ \\
\hline $\begin{array}{l}\text { 2. Partnerships with scientists or industry outside of } \\
\text { Africa }\end{array}$ & Isolated collaborations aimed at developing candidate gene therapies \\
\hline 3. Regulatory oversight & No or little experience with implementing gene therapy \\
\hline 4. Funding for material resources & Largely inadequate for developing gene therapy-based drugs \\
\hline $\begin{array}{l}\text { 5. Material research infrastructure, including } \\
\text { specialized equipment }\end{array}$ & Pockets of well-resourced facilities \\
\hline 6. Capacity for toxicological evaluations & Adequate in parts of the continent \\
\hline $\begin{array}{l}\text { 7. Legal support for development of intellectual } \\
\text { property }\end{array}$ & Excellent in major cities of the continent \\
\hline \multicolumn{2}{|l|}{ Clinical use (pre- and post-trial) } \\
\hline 1. Regulatory oversight & No or little experience with gene therapy \\
\hline $\begin{array}{l}\text { 2. Manufacturing capabilities for large-scale } \\
\text { production }\end{array}$ & $\begin{array}{l}\text { Existing production facilities geared mainly to develop small molecule drugs, limited } \\
\text { capability for production of biologicals }\end{array}$ \\
\hline 3. Appropriate storage of gene therapies & Good in urban areas, but maintenance of cold chain in rural areas is often limited \\
\hline $\begin{array}{l}\text { 4. Compliance with regulations of good } \\
\text { manufacturing practice }\end{array}$ & $\begin{array}{l}\text { Limited experience with compliance with production of gene therapy candidates, but } \\
\text { good capabilities with small molecule drug manufacture }\end{array}$ \\
\hline $\begin{array}{l}\text { 5. Patient management, monitoring and record } \\
\text { keeping }\end{array}$ & $\begin{array}{l}\text { Excellent in major centers where there is extensive experience with global multicentre } \\
\text { clinical trials }\end{array}$ \\
\hline
\end{tabular}

atrophy, $^{12}$ Gendicine, for the treatment of head and neck squamous cell carcinoma, ${ }^{13}$ Glybera, for the correction lipoprotein lipase deficiency, ${ }^{14}$ and Imlygic, for the treatment of melanoma lesions. ${ }^{15}$ Nevertheless, when gene therapy reaches the mainstream of disease treatment, it is likely to be important for management of diseases that affect the African continent particularly. Capacity development to enable Africans to tackle health problems of Africa is vital to the future of gene therapy on the continent. Key to success of any gene therapy program in Africa is government endorsement, ensuring sustainability, community engagement, enactment of appropriate regulatory legislation and rewarding of entrepreneurship. Although there are many research and diagnostic laboratories that carry out work on gene therapy-affiliated scientific topics, such as genetic analysis of African populations, there are very few research laboratories in Africa that specialize in work on developing gene therapy drugs. Africa has made significant progress with advancing stem cell therapy, and several laboratories focus on this therapeutic approach. $^{16}$ To our knowledge, the Antiviral Gene Therapy Research Unit of the South African Medical Research Council and University of the Witwatersrand (Wits/SAMRC AGTRU) in Johannesburg is the only lab in Africa that specialises in gene therapy research. The Institute for Cellular and Molecular Medicine (ICMM) at the University of Pretoria and the School of Life Sciences at the University of KwaZulu-Natal also pursue research themes on the topic of gene therapy. Issues related to the shortage of human resources (discussed above), funding for the maintenance of research laboratories and limited partnerships with international collaborators all contribute to the problem.

The dearth of resources in African countries is further complicated by inequalities within countries. For example, South Africa is the country with the highest Gini coefficient and unequal distribution of income translates to provision of health care that markedly favors the wealthy. Ensuring that there is fair allocation of resources within countries and over the continent will be challenging. Working towards this distributive justice, as well as by working within a framework of sound principles of health economics, will be important to safeguard benefits of hightechnology medicine for African communities. Little if any research has been carried out to estimate the future benefits of implementing gene therapy in Africa and other parts of the world. This has been compounded by the fact that gene therapeutics are currently very expensive. ${ }^{17,18}$ This point is clearly highlighted by the case of Glybera, which has a price tag of approximately U\$ $1 \mathrm{M}$ for a single administration. Similar issues regarding the pricing and efficacy of Imlygic have limited its widespread use. ${ }^{19}$ The roll-out of Strimvelis, a cell-based therapy for the treatment of adenosine deaminase-severe combined immunodeficiency, appears more encouraging and this has been related to robust data on efficacy of the therapeutic and reasonable pricing plans. ${ }^{19}$ Furthermore, the data suggest that the pricing of Strimvelis is significantly lower than of the alternative of enzyme replacement therapy. When the field matures, it is likely that bringing modern and powerful technology into the mainstream of medical practice will lower costs of gene therapy.

\section{THE BURDEN OF DISEASE IN AFRICA}

The global burden of disease has changed significantly during the past few decades. ${ }^{20}$ The general trend has been that people are living longer, deaths resulting from communicable diseases are declining and mortality from non-commmunicable diseases is increasing. The changes in sub-Saharan Africa have however been less significant. Although non-communicable diseases are increasing in this region, infectious, nutritional, perinatal infant and maternal diseases remain major contributors to mortality. Deaths from measles and tetanus have declined significantly throughout the region. However HIV/AIDS, malaria, infectious hepatitis and tuberculosis are major contributors to mortality and morbidity on the continent. ${ }^{20,21}$ Interventions to counter burdens of disease are best prioritized according to the most cost effective means of limiting morbidity and mortality from the commonest diseases. Attention to appropriate primary health care, vaccination, basic sanitation, behavioral modification, pre- and post-natal care have greatest impact. Implementing gene therapy, which is correctly perceived to be a costly and sophisticated treatment option, will require careful assessment of the impact of such an intervention.

The concept of false dichotomies in global health ${ }^{22}$ is apposite when considering the usefulness of gene therapy in Africa. In their recent publication, Frenk and Gomez-Dantes propose that the complexity of global health-care needs requires integrated and comprehensive strategies to be most effective. Until recently, health priorities were determined by what appeared to be opposing viewpoints. Examples of these so-called dichotomies 
include primary as opposed to specialized care, and prevention versus cure. Integration of these apparently polarized approaches is, however, important to create synergy to improve overall management of disease. Treatment of HIV-1-infected individuals is an easily understood example that illustrates the point. Although efforts to modify behavior have diminished spread of the virus, prognosis for untreated individuals who are already infected with the virus is grave. Suppressing HIV-1 replication through the use of combination antiretroviral therapy dramatically improves prognosis, renders individuals less infectious and therefore curtails transmission. However, cure from HIV-1 infection would be ideal to obviate the current requirement for long-term administration of antiretrovirals. The advances with gene therapy have demonstrated that cure from the serious infection is a possibility and is discussed below in more detail.

\section{GENE THERAPY FOR TREATING DISEASES OF AFRICAN IMPORTANCE}

Although most gene therapy research aimed at treating conditions that are common to Africa has been performed outside of the continent, considerable progress has been made with developing the technology to counter diseases of African importance. Using gene therapy to inactivate viruses, eliminate cancers and treat inherited diseases is likely to be feasible in the long term. Progress against selected examples of diseases that are significant in the African continent is discussed below.

\section{Gene therapy for viral infections}

Viruses remain a significant cause of mortality and morbidity in Africa. In a broad context, advancing new treatments has been impressive and many viral infections are now managed effectively. An example is the use of directly acting antivirals for curative treatment of hepatitis $C$ virus infection. ${ }^{23-26}$ However, although treatment of HBV and HIV-1 may suppress viral replication, licensed drugs do not eliminate the viruses. Gene therapy has the potential to eliminate these pathogens and has therefore generated considerable enthusiasm. Infections by HIV-1, HBV and Ebola virus, particularly common in sub-Saharan Africa, are discussed in more detail below.

Gene therapy for HIV-1 infection. Infection with HIV-1 and progression to AIDS emerged as a serious public health problem in the 1980s. Sub-Saharan Africa was, and still is, particularly seriously affected by the pandemic. In 2014 there were approximately 790000 deaths in this region as a result of
AIDS (http://www.who.int/gho/hiv/epidemic_status/deaths_text/ en/). Improved access to combination antiretroviral therapy has limited AIDS development in HIV-1-infected individuals. Nevertheless, difficulties with eliminating the virus and slow progress of vaccination strategies have meant that the infection and its complications remain a significant public health problem in Africa.

Advances with using gene therapy to achieve durable suppression of HIV-1 replication have stimulated interest in applying this technology. Enthusiasm for gene therapy to treat HIV-1 infection is partly derived from the success with eliminating HIV-1 from the so-called 'Berlin patient'. ${ }^{27,28}$ After bone marrow ablation to treat acute myeloid leukemia, this HIV-1-infected individual received an allogenic bone marrow transplant from a matched donor who was homozygous for mutant CCR5, an HIV-1 co-receptor. Donor cells were thus resistant to CCR5-tropic HIV-1 infection and the Berlin patient has been free from HIV-1 without the need for antiretrovirals. Although this is a particularly impressive achievement, widespread use of allogenic bone marrow transplant is problematic because of the difficulty with finding matched donors with the double $c c r 5-\Delta 32 / c c r 5-\Delta 32$ mutations. To address this problem, gene editing is being employed in an attempt to disable ccr5 and render autologous cells resistant to HIV-1 infection. ${ }^{29,30}$ Repeated cleavage of the target ccr5 sequence leads to repair by error-prone non-homologous end joining and eventual mutation of the target. The clustered regularly interspaced short palindromic repeats (CRISPR) with CRISPR-associated (Cas) system, Zinc finger nucleases and transcription activator-like effector nucleases have all been employed to achieve target-specific cleavage and inhibition of HIV-1 replication (reviewed in Arbuthnot ${ }^{31}$ ). The favored strategy is to employ ex vivo modification of autologous hematopoietic stem cells (Figure 1). Modified hematopoietic stem cells may then be expanded before re-infusion into the patient. As a variation of the procedure, induced pluripotent stem cells may be used. The underlying principle is that stem cells retain the capability of self-renewal. The treated individual may therefore have a reconstituted immune system that comprises cells that are resistant to infection with the virus. In addition to mutating host factors such as CCR $5,{ }^{10}$ which are required for HIV-1 entry into host cells, strategies aimed at disabling viral sequences directly have also been used. ${ }^{32,33}$ Although inactivation of the provirus has been observed, delivery of gene editors to all reservoirs of latently infected cells remains challenging.

Harnessing the RNA interference (RNAi) pathway is another gene-inactivating strategy that has been investigated for antiHIV-1 therapeutic application (reviewed in Berkhout et al., ${ }^{34}$ Burnett ${ }^{35}$ ). As with gene editing, artificial RNAi activators have
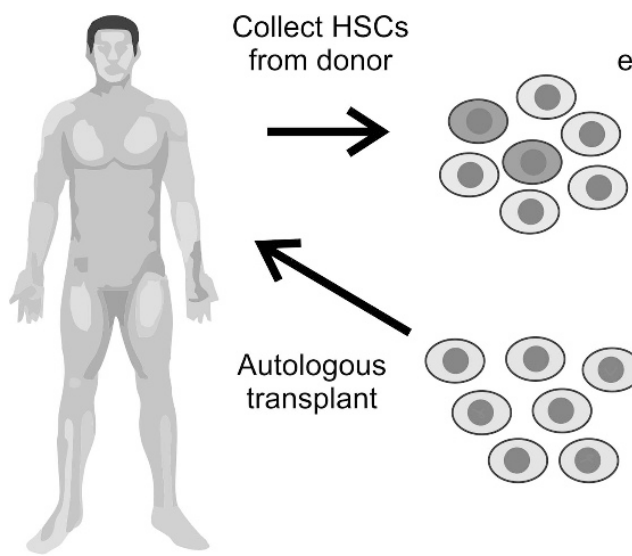

Select and expand CD34+
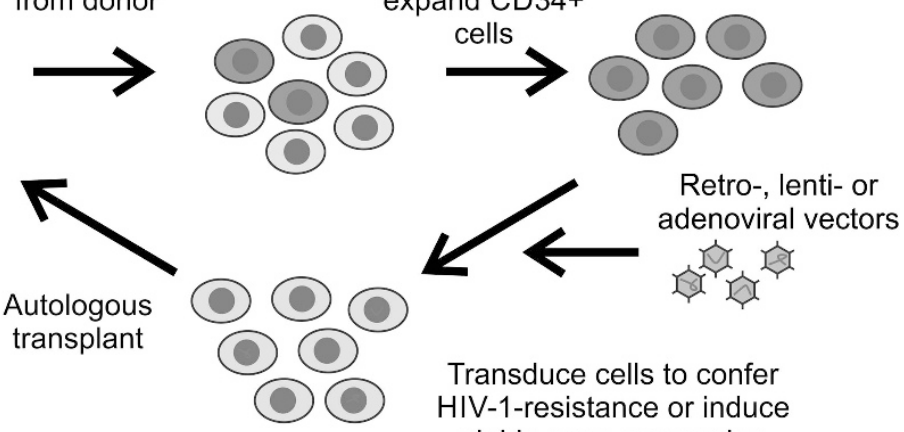

Transduce cells to confer

HIV-1-resistance or induce globin gene expression

Figure 1. Modification of cells ex vivo. Cells are collected and expanded in culture following selection. Transduction with vectors is employed to introduce a therapeutic sequence which may, for example, confer resistance to HIV-1 or induce expression of a globin gene. The selected cells may be re-infused into the donor by autologous transplant. Use of hematopoietic stem cells enables formation of self-renewing precursor cells that generate progeny with the desired phenotype. 


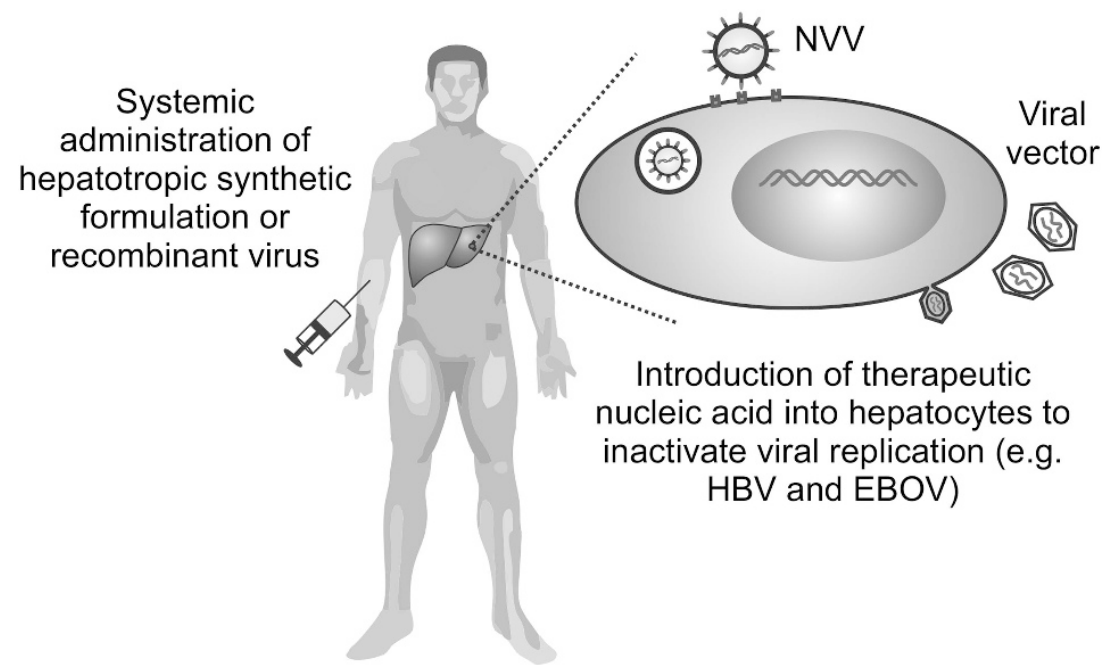

Figure 2. Delivering antiviral sequences using viral vectors or NVVs. Following systemic administration, viral vectors and NVVs target hepatocytes, where the therapeutic sequences are delivered. Typically NVVs enter the liver cells by endocytosis. The approach is useful to effect a therapeutic action against HBV or hemorrhagic fever viruses such as EBOV.

been used to target host factors or viral sequences and impede viral replication. ${ }^{9}$ Since RNAi activators function at a posttranscriptional level of gene expression, long-term action of the gene silencers is necessary to achieve durable suppression of viral replication. Combinatorial approaches have been employed to counter the emergence of viral escape. Use of expression cassettes that generate mimics of the RNAi pathway may thus be preferable to administration of synthetic exogenous RNAi activators, which have a transient effect on viral replication. The effect of sustained expression of RNAi activators on cellular function is not yet comprehensively established, and unintended off-target effects may well occur. Strategies to overcome induction of an immune resonse by dsRNA, unintended binding of the exogenous RNAi effectors to cellular targets, cytotoxicity and saturation of the endogenous pathway remain important considerations. ${ }^{36-38}$

Gene therapy for HBV infection. Chronic infection with HBV occurs in 240 million people, and the infection is hyperendemic to subSaharan Africa. ${ }^{39-42}$ Life-threatening complications, which include cirrhosis and hepatocellular carcinoma, occur commonly in carriers of the virus. Although effective vaccines are available to prevent HBV infection, they have no therapeutic benefit and are of no use to individuals who are already infected with the virus. Use of gene transfer to induce immunity against the virus has shown promise and is discussed below. Complications of chronic HBV infection remain a significant public health problem of particular relevance to Africa. Despite widespread vaccination programs, global mortality from HBV infection increased over the period from 1990 to 2013 and 700000 people died in 2013 as a result of complications of HBV infection. ${ }^{21}$ Available licensed therapies for HBV infection include reverse transcriptase inhibitors and derivatives of interferon-alpha (IFN- $a$ ). These drugs are capable of suppressing HBV replication, but rarely eliminate the virus from virus-infected individuals. The main reason for the shortcomings of current treatments is the stability of the viral replication intermediate comprising covalently closed circular DNA (cccDNA). This cccDNA, which serves as the template for expression of viral genes, is unaffected by nucleoside and nucleotide analogs and is rarely eliminated in IFN-a-treated carriers. Persistence of the virus therefore results in continued risk of mortality from complicating cirrhosis and hepatocellular carcinoma.

Research on applying gene therapy to treat HBV infection shows promise. As with advancing treatment of HIV-1 infection, both gene silencing and gene editing have potential (reviewed in
Dever et al., ${ }^{43}$ Ivacik et al., $\left.{ }^{44}\right)$. HBV has an unusually compact genome with overlapping open reading frames. As a result, the cccDNA has restricted sequence plasticity, and unlike with HIV-1, viral escape is unusual. Targeting cccDNA with engineered sequence-specific nucleases, such as Zinc finger nucleases, ${ }^{45-47}$ transcription activator-like effector nucleases ${ }^{7,48}$ and CRISPR/ $\mathrm{Cas}^{49-52}$ provide a way of permanently disabling the replication intermediate. Several studies have shown that targeted mutagenesis disables HBV DNA and thereby provides a means for eliminating HBV from chronically infected individuals. Advancing the technology to a stage of evaluation in a clinical setting is currently a priority. This next step is faced with challenges of safe and efficient delivery of therapeutic sequences to HBV-infected hepatocytes following systemic administration (Figure 2), and verifying specificity of action of the gene editors. Sequences encoding potentially therapeutic CRISPR/Cas, dimeric Zinc finger nucleases and transcription activator-like effector nucleases are long and not easily accommodated by the popular adenoassociated viral vectors. Alternative approaches, such as formulating mRNA encoding the gene editors in synthetic non-viral vectors (NVVs), may be necessary.

Activating RNAi for therapeutic inhibition of HBV gene expression has been an active field of research (reviewed in Ivacik et $\left.a l .{ }^{44}\right)$. Synthetic siRNAs, with and without chemical modifications, incorporated into hepatotropic NVVs, have been used successfully to inhibit replication of the virus. $8,53,54$ Expressed RNAi activators, which include short hairpin RNAs, ${ }^{55,56}$ long hairpin $\mathrm{RNAs}^{57}$ and single ${ }^{5,58}$ and multimeric artificial microRNAs (miRs) ${ }^{6}$ have also demonstrated good efficacy against the virus. Interestingly the evidence that expressed short hairpin RNAs are capable of inhibiting HBV replication in vivo was the first demonstration that RNAi has antiviral potential. ${ }^{56}$ Use of HBV-targeting RNAi activators has now reached a stage of testing in clinical trials. ${ }^{59}$ Although preclinical evaluation has shown promise, it remains to be established whether the long-term efficacy is sufficient to achieve a cure.

Gene therapy undoubtedly has the potential to cure HBV infection. However the challenges that face clinical translation of most gene therapies also apply to HBV treatment. Efficient delivery, avoidance of toxicity, limiting immunostimulation and ensuring specificity of action are all important. For large-scale use in patients, synthetic formulations are likely to be necessary, and to be useful in sub-Saharan Africa, they will need to be affordable, stable and easily administered. Regimens that include 
combinations of licensed drugs with gene therapies will be interesting to evaluate and may improve efficacy.

Gene therapy for hemorrhagic fever viruses. Sporadic outbreaks of infections with hemorrhagic fever viruses (HFVs) have been a major concern in parts of sub-Saharan Africa. Hemorrhagic fever is very serious, and the condition is characterized by sudden onset of symptoms that rapidly progress to bleeding, shock and multiorgan failure with associated high mortality. The Ebola virus (EBOV) epidemic that commenced in Guinea in December 2013, and which then spread to Liberia and Sierra Leone was particularly severe. The virus claimed the lives of in excess of 11000 people in West Africa (https://www.cdc.gov/vhf/ebola/outbreaks/2014-westafrica/case-counts.html). Marburg virus is another member of the Filovirus family of HFVs that is encountered most frequently in Africa. Given the often lethal nature of the infection with HFVs and their potential global impact, developing vaccines and effective antivirals is understandably a priority. Early clinical features of viral hemorrhagic fevers are usually not pathognomonic of the infection and early diagnosis is therefore difficult. Management is currently limited to being supportive and containment of infected individuals is vital to prevent spread. The rational design that forms the basis of gene therapies is particularly useful to disable HFVs and many investigations have shown that gene therapy has promise for the treatment of these serious infections.

The pathogens that cause hemorrhagic fevers are RNA viruses which replicate in the cytoplasm of infected cells. Exploiting RNAi to inactivate replication has therefore been a logical approach to advancing gene therapy to treat the infections. However, an important feature of infection with EBOV is that the viral VP35 protein inhibits the RNAi pathway. ${ }^{60}$ To overcome this effect, the VP35 sequence itself has been the target of strategies employing RNAi to inhibit EBOV replication. ${ }^{61}$ Given the acute nature of HFV infections, sustained RNAi-mediated silencing is less important than it is with HIV-1 or HBV infection. A very promising preclinical study showed that synthetic siRNAs, formulated in hepatotropic NVVs, protect macaques from lethal exposure to EBOV. ${ }^{61}$ Although several different types of human cells are permissive for infection with EBOV, replication of the virus occurs mainly in the liver, which is the rationale for using hepatotropic NVVs (Figure 2). Approaches that employ RNAi to disable replication of Marburg virus have also shown therapeutic potential. Synthetic siRNAs, formulated in hepatotropic NVVs, afforded good protection to guinea pigs ${ }^{62}$ and in Rhesus macaques ${ }^{63}$ following lethal challenge. Rift Valley Fever Virus, another potentially serious HFV, has also been shown to be susceptible to RNAi-based inhibition. ${ }^{64}$

The serious nature of infections with EBOV and Marburg virus makes it impractical to evaluate new drugs to treat these infections in conventional clinical trials. The United States Food and Drug Administration thus devised the 'Animal Rule' (reviewed in $S$ noy ${ }^{65}$ ), which enables clinical use of drugs that show good efficacy in animal studies. Since efficacy of nucleic acid-based treatments of EBOV and Marburg virus have been convincingly demonstrated in macaques, the case for initiating gene therapy to treat HFV infections is compelling. Although commendable, practical issues relating to rapid implementation on a large scale in affected African populations may currently be difficult. The recent outbreak of EBOV during 2014-2015 highlights how the 'Animal Rule' could have been employed. Efforts were underway to fast-track candidate vaccines and engagement between African and international stakeholders facilitated this process. ${ }^{66}$ However, since clinical data on efficacy are normally required for licensing, these interventions were never used during the EBOV outbreak, ${ }^{67}$ which endorses the merits of pursuing less traditional licensing routes, such as the 'Animal Rule'.
Nucleic acids as vaccines

For many years, vaccination has been the cornerstone of protecting against infectious diseases. The rationale is that administration of an immunogen, which may be a recombinant protein, or a killed or attenuated pathogen, induces memorized immunity to the pathogen without the risk of disease. Delivery of nucleic acids, such as those that may be engineered within recombinant viral vectors or synthetic formulations, have recently gained popularity as immunogens. Use of DNA encoding immunogens has been an active field of research, ${ }^{68}$ and early studies showed usefulness of the approach in preventing HBV infection. ${ }^{69-71}$ Recombinant viruses, such as engineered replication defective adenoviruses (Ads) and poxviruses (reviewed in Arbuthnot ${ }^{31}$ ), have now gained popularity. These vectors deliver immunogenic sequences efficiently and are capable of inducing powerful cytotoxic $T$ lymphocyte responses. Ads and poxviruses are now well understood and it is possible to manipulate their genomes to encode various immunogens and confer a variety of preferred biological properties. A drawback of recombinant viral vectors is that they are themselves immunogenic. The Step HIV vaccination trial highlighted a particularly serious consequence of the immunostimulatory effects of Ads. ${ }^{72}$ The vaccine, termed MRKAd5, comprised a serotype 5 Ad vector that encoded gag, pol and nef sequences of HIV-1 subtype B. The initial study entailed administration of the vaccine to non-African residents in parts of the world where clade B is the predominant HIV-1 subtype. Contrary to the intended effect, patients receiving the vaccine had a slightly higher risk of acquiring HIV-1 infection. The effect may have been a result of a predeliction of HIV-1 for T cells that had been activated by the vaccine. The subsequent HVTN503/Phambili trial analyzed administration of MRKad5 to South African subjects, where clade $C$ is commonest. ${ }^{73}$ The study was however halted after outcome of the Step trial became available. ${ }^{72}$ Although early termination of the investigation limited ability to draw conclusions, the MRKAd5 vaccine did not appear to prevent HIV-1 infection in the South African subjects. ${ }^{73}$ Subsequent investigations attempted to augment anti-HIV-1 immunogenicity by employing a prime-boost strategy in individuals from South Africa $^{74}$ and the USA. ${ }^{75,76}$ Subjects initially received a 6-plasmid DNA vaccine encoding Gag, Pol and Nef from clade B, and Env from clades A, B and C. Recombinant Ad5-encoding clade B GagPol fusion and Env from clades $A, B$ and $C$ was therafter given as a booster. Although the vaccination regimen induced humoral and cell-mediated immune responses, prevention of viral infection was not established. Another consideration relevant to developing Ad5-based vaccines is that pre-existing immunity to adenoviruses of this serotype occurs commonly. Ad26-based vaccines, which are distinct from Ad5 and bypass immunity to this serotype, ${ }^{77}$ are thus now being tested in clinical trials to develop vaccines against HIV-1. ${ }^{78-80}$

A major advantage of employing nucleic acid transfer rather than recombinant protein administration is that cell-mediated as well as humoral immunity are induced. Expression of immunogens within cells simulates pathogens' gene expression in infected cells. Encoded proteins may be presented on the cell surface by major histocompatability complex class I receptors, which in turn lead to activation of cytotoxic T cells. With recombinant proteins, it is typically only the humoral arm of the immune response that is activated. This occurs following major histocompatability complex class II-mediated interaction of antigen-presenting cells with $T$ helper cells and stimulation of B cell maturation to form antibody-producing plasma cells. Following intramuscular or intradermal administration of nucleic acid vectors, myocytes, dendritic cells and monocytes may take up and express the encoded immunogen. This results in major histocompatability complex class I and major histocompatability complex class II activation with stimulation of cytotoxic $T$ cells and proliferation of 
plasma cells to effect activation of cell-mediated and humoral immunity. ${ }^{68}$

Preventative or therapeutic immunization using gene transfer has many advantages that are particularly relevant to an African setting. Some include the following:

1. The vaccines are generally safe, not toxic and the nucleic acids that are formulated within synthetic NVVs are usually not antigenic.

2. Manipulation and preparation of DNA employs procedures that are standard, and preparation of sufficient amounts required for widespread vaccination programs is typically uncomplicated.

3. Incorporation of additional sequences to augment immunostimulation is feasible.

4. It is possible to include adjuvants, such as oligonucleotides that activate Toll-like receptors to enhance immunostimulation.

Immunomodulatory effects using gene trasnfer are also gaining popularity for cancer treatment. Using gene therapy to adapt principles of passive immunization also has utility. Sequences encoding broadly neutralizing antibodies (nNAbs), which are active against a range of HIV-1 isolates, have been incorporated into recombinant adeno-associated viral vectors. ${ }^{81}$ This approach, termed vectored immunoprophylaxis, is capable of protecting against HIV challenge in humanized mice.

\section{Gene theapy for inherited diseases common to Africa}

There is a myriad of inherited diseases that is particular to Africa, and the African diaspora led to its global dispersement. Although they have a variable distribution throughout Africa, two of the more common inherited disorders on the continent are sickle cell disease and glucose-6-phosphatase deficiency. Sickle cell disease results from a homozygous transversion substitution in the first exon of the $\beta$-globin gene (reviewed in Hossain et $a l^{82}$ ). The affected codon in the changed sequence encodes a valine amino acid instead of glutamic acid. A heterozygous state of the sickle gene provides protection against malaria and the mechanism is thought to involve preferential removal of Plasmodium falciparuminfected red blood cells by macrophages. When homozygous, the mutation results in serious pathology that manifests as sickle cell disease. Sickling of red blood cells results from polymerization of hemoglobin following deoxygenation. These red blood cells have a short life span, and cause endothelial and end organ damage with resultant high mortality and morbidity.

Allogenic stem cell transplantation has been used successfully to treat sickle cell disease, but finding matched donors is difficult. Investigating use of gene therapy to counter the defect has thus become a popular line of research (reviewed in Marimani et al. ${ }^{8}$ ). Safe and efficient globin gene expression together with appropriately regulated transgene expression in progenitors of red blood cells are vital. Gene addition to target cells, expression of alternative globin genes, reactivation of fetal globin genes and gene editing have all been investigated as therpaeutic options. Two promising approaches entail gene editing to inactivate $B C L 11 \mathrm{~A}$ expression ${ }^{83}$ or stimulation of homology directed repair to restore the normal sequence of the $\beta$-globin gene. ${ }^{43,84} \mathrm{BCL} 11 \mathrm{~A}$ is a repressor of $Y$-globin gene expression in the adult. Monoallelic inactivation of the target of BCL11A within the $Y$-globin gene increases its expression to achieve a therapeutic effect. ${ }^{82,83}$ Application of autologous hematopoietic stem cell modification and re-infusion (Figure 1) is also a feasible mode of treatment.

Gene therapy for primary immunodeficiencies is currently an area of vigorous research. Although gene therapy for primary immunodeficiencies in Africa has received very little attention, programs for managing primary immunodeficiencies in Africa have been established (http://www.sun.ac.za/engli sh/faculty/healthsciences/Molecular_Biology_Human_Genetics/pi ddgen). This capability may provide an entry point for establishment of gene therapy platforms, which may also be used to facilitate treatment of more common diseases discussed above.

\section{FUNDING AND PARTNERSHIPS TO FACILITATE RESEARCH ON GENE THERAPY IN AFRICA}

Gene therapy is a complex field, which is very demanding of material and human resources. Adequate funding and strategic partnerships are thus essential to provide a base to facilitate meaningful progress in Africa. Government support is variable throughout the continent and information is not readily available on specific details about the resources that have been devoted to advancing gene therapy on the continent. South African funding agencies, which have been particularly generous with their backing, include the South African Medical Research Council, National Research Foundation and Department of Science and Technology. Funds coming from outside of Africa, typically provided to research partnerships involving African researchers, have also been valuable. The US National Institutes of Health $(\mathrm{NIH})$, Wellcome Trust and European Commission have sponsored teams that include African researchers working on gene therapy.

The H3Africa initiative (http://www.h3africa.org/) is a shining example of how properly channeled and monitored international funding can be used effectively to build capacity in fields related to gene therapy. A requirement for support from the funding agency is that the principal investigator should reside on the African continent and she/he should address problems that are relevant to its peoples. The program receives funding from the $\mathrm{NIH}$ and the Wellcome Trust. A first round of funding was initiated in 2012 and a second round, which is also supported by GlaxoSmithKline (GSK) (London, UK), began in 2016/2017. The second round funding is being administered by the The Alliance for Accelerating Excellence in Science in Africa (AESA http://aasciences.ac.ke/aesa/programmes/h3africa/funding-oppor tunities/), which is an initiative of the African Academy of Sciences (AAS) and the New Partnership for Africa's Development (NEPAD) Agency. AESA has recently also solicited applications for Grand Challenges Africa (GCA) (http://aasciences.ac.ke/aesa/en/pro grammes/grand-challenges-africa/), which aims to promote 'Africa-led scientific innovations to help countries better achieve the Sustainable Development Goals by awarding seed and full grants to the continent's most impressive solutions'. Funding for the GCA initiative is provided by the Bill and Melinda Gates Foundation.

An African initiative that includes support for gene therapy within the program, is the African Network for Drugs and Diagnostics Innovations (ANDI) (www.andi-africa.org or http:// www.who.int/tdr/partnerships/initiatives/andi/). This project has been supported by several partners including the World Health Organization and several institutions from countries throughout Africa. The main objective of ANDI is 'to promote and sustain African-led health product innovation to address African public health needs through efficient use of local knowledge, assembly of research networks, and building of capacity to support economic development'. The initiative was launched in 2008 and the network was formed through an association of several African laboratories that were considered Centers of Excellence. To date, ANDI has carried out a facilitating function rather than as a direct funder of research. However, attracting significant and sustained funding to drive efforts aimed at attaining the intended goals is a necessity for the program to thrive.

Partnerships with industry to develop specific gene therapies are rare in Africa. One example is the collaboration that has recently been established between Johnson \& Johnson 
Innovation, based in Boston, MA, USA, and the Antiviral Gene Therapy Research Unit located at the University of the Witwatersrand in Johannesburg, South Africa (http://www.prnews wire.com/news-releases/johnson--johnson-innovation-announces17-collaborations-with-focus-on-advancing-global-healthcare-thro ugh-transformational-science-and-technologies-300097578.html). The cooperative research carried out by the two groups aims to develop gene therapy for treatment of chronic HBV infection. The initiative is a good example of support for African scientists who aim to tackle a disease of particular importance to Africa. Importantly, such partnerships hinge on offering the industry partner well-developed expertise and highlight the advantage for Africa to invest in research and development. The ability to manage and generate intellectual property are additional significant factors that motivate industry to partner with the researchers in the African research setting.

\section{CONCLUSIONS}

Although there are very few licensed gene therapies, the technology is poised at an interesting phase of development. Useful properties of the methods employed are based on rational design principles and versatility that enables application to treatment of many diseases. It is important for Africa that gene therapy is potentially applicable to several diseases that cause serious public health problems of the continent. There are however challenges that are impeding global progress of gene therapy to the mainstream of clinical application. Successful translation of gene therapy is particularly dependent on achieving efficient delivery of therapeutic nucleic acids to target tissues, limiting toxicity and ensuring specificity of action of candidate therapeutics.

In addition to the technical hurdles that need to be overcome, there are other factors that will influence the utility of gene therapy in Africa. Efficacy of alternative preventative or therapeutic management is important. Recent development of directly acting antivirals that cure hepatitis $C$ virus infection means that use of gene therapy to eliminate the virus is less likely (discussed above). Nevertheless, gene therapy has an important role when curative small molecule drugs are not available. Diseases caused by HIV-1 and HBV are examples where gene therapy may well be important to eliminate viral infections of African importance. In the case of HBV persistence, the problematic cccDNA is stable and unaffected by currently licensed drugs. Employing a gene editing approach provides the means to disable this viral transcription template. Gene editing may also be employed to render $\mathrm{CD}^{+}$ T cells resistant to HIV-1 infection and inactivate the proviral DNA.

A major factor influencing the long-term prospects of gene therapy in Africa relates to the practicalities of using the technology in resource-poor settings. Gene therapy drugs are complex and costly to produce and administer. Their use in settings where financial resources are constrained is therefore moot. Most protocols are specialized and sophisticated facilities for preparation and administration of gene therapies are necessary. An example is the technology that is being developed for ex vivo modification of hematopoietic stem cells before autologous grafting (Figure 1). The strategy is elegant and results suggest that the approach may be coupled to gene editing to render cells resistant to HIV-1 infection. However very few centers in Africa are equipped to carry out such procedures. Ideally, the methodology will become cheaper and protocols will be simplified. Moreover, with progress of the technology, development of new candidate drugs should be rapid. This will be particularly useful to counter emerging pathogens and serious outbreaks such as have been caused by EBOV and severe acute respiratory syndrome coronavirus. In addition to technical challenges, lack of legal frameworks that regulate use of gene therapy may also hinder Africa deriving benefit from this technology. Implementating comprehensive legislation that will govern gene therapy research and translation into the clinic remains imperative. The diverse religious, ethical and moral beliefs in Africa also need to be accommodated. Despite these hurdles, implementing the legal framework for gene therapy may be informed by prior experiences of developing regulations pertaining to biotechnology and use of stem cell therapy in Africa. ${ }^{85}$

Participation of developing countries, especially those of Africa, in the implementation of gene therapy will be exciting and valuable. This extends to regulation of gene therapy, which is nonexistent or is loosely covered by legislation relating to biotechnology. Ensuring appropriate legislation is in place for implementing gene therapy is paramount to eventually realizing the potential of this field in Africa. Involving African countries in the process will improve the capacity for modern medically applied molecular biology, assist with tackling health problems of the continent effectively, and enable knowledge-based economies to develop. Activities in the field of gene therapy in Africa are currently modest. However, strengthening the endeavor should be a priority that will be of extensive benefit to the continent.

\section{CONFLICT OF INTEREST}

$\mathrm{PA}, \mathrm{MBM}$ and $\mathrm{AE}$ receive funding from Johnson \& Johnson Innovation. MSP does not declare any conflict of interest.

\section{ACKNOWLEDGEMENTS}

Financial assistance for work carried out in the authors' laboratories, which was received from the South African National Research Foundation (NRF, GUNs 81768, 81692, 68339, 85981, 77954 and 61508), the South African Medical Research Council, the Swiss-South African Joint Research Program, Johnson \& Johnson Innovation and the South African Poliomyelitis Research Foundation (PRF-15/27) is gratefully acknowledged.

\section{REFERENCES}

1 Friedmann T, Roblin R. Gene therapy for human genetic disease? Science 1972; 175: 949-955.

2 Collins M, Thrasher A. Gene therapy: progress and predictions. Proc Biol Sci 2015; 282: 20143003.

3 Naldini L. Gene therapy returns to centre stage. Nature 2015; 526: 351-360.

4 Lowe M, Chen DR. Factors influencing the migration of West African health professionals. Pan Afr Med J 2016; 24: 237.

5 Ely A, Naidoo T, Mufamadi S, Crowther C, Arbuthnot P. Expressed anti-HBV primary microRNA shuttles inhibit viral replication efficiently in vitro and in vivo. Mol Ther 2008; 16: 1105-1112.

6 Ely A, Naidoo T, Arbuthnot P. Efficient silencing of gene expression with modular trimeric Pol II expression cassettes comprising microRNA shuttles. Nucleic Acids Res 2009; 37: e91.

7 Bloom K, Ely A, Mussolino C, Cathomen T, Arbuthnot P. Inactivation of hepatitis B virus replication in cultured cells and in vivo with engineered transcription activator-like effector nucleases. Mol Ther 2013; 21: 1889-1897.

8 Marimani MD, Ely A, Buff MC, Bernhardt S, Engels JW, Scherman D et al. Inhibition of replication of hepatitis $B$ virus in transgenic mice following administration of hepatotropic lipoplexes containing guanidinopropyl-modified siRNAs. J Control Release 2015; 209: 198-206.

9 Myburgh R, Ivic S, Pepper MS, Gers-Huber G, Li D, Audige A et al. Lentivector knockdown of CCR5 in hematopoietic stem and progenitor cells confers functional and persistent HIV-1 resistance in humanized mice. J Virol 2015; 89: 6761-6772.

10 Barmania F, Pepper MS. C-C chemokine receptor type five (CCR5): an emerging target for the control of HIV infection. Appl Transl Genom 2013; 2: 3-16.

11 van der Loo JC, Wright JF. Progress and challenges in viral vector manufacturing. Hum Mol Genet 2016; 25: R42-R52.

12 Jablonka S, Sendtner M. Developmental regulation of SMN expression: pathophysiological implications and perspectives for therapy development in spinal muscular atrophy. Gene Ther 2017; 24: 506-513.

13 Pearson S, Jia H, Kandachi K. China approves first gene therapy. Nat Biotechnol 2004; 22: 3-4. 
14 Yla-Herttuala S. Endgame: glybera finally recommended for approval as the first gene therapy drug in the European union. Mol Ther 2012; 20: 1831-1832.

15 Pol J, Kroemer G, Galluzzi L. First oncolytic virus approved for melanoma immunotherapy. Oncoimmunology 2016; 5: e1115641.

16 Jackson CS, Pepper MS. Opportunities and barriers to establishing a cell therapy programme in South Africa. Stem Cell Res Ther 2013; 4: 54

17 Brennan TA, Wilson JM. The special case of gene therapy pricing. Nat Biotechnol 2014; 32: 874-876.

18 Touchot N, Flume M. The payers' perspective on gene therapies. Nat Biotechnol 2015; 33: 902-904.

19 Touchot N, Flume M. Early insights from commercialization of gene therapies in Europe. Genes (Basel) 2017; 8: 78.

20 Institute for Health Metrics and Evaluation. The global burden of disease: generating evidence, guiding policy. IHME: Seattle, WA, 2013.

21 Stanaway JD, Flaxman AD, Naghavi M, Fitzmaurice C, Vos T, Abubakar I et al. The global burden of viral hepatitis from 1990 to 2013: findings from the Global Burden of Disease Study 2013. Lancet 2016; 388: 1081-1088.

22 Frenk J, Gomez-Dantes O. False dichotomies in global health: the need for integrative thinking. Lancet 2017; 389: 667-670.

23 Cooper C, Lester R, Thorlund K, Druyts E, El Khoury AC, Yaya S et al. Direct-acting antiviral therapies for hepatitis $C$ genotype 1 infection: a multiple treatment comparison meta-analysis. QJM 2013; 106: 153-163.

24 Lawitz E, Mangia A, Wyles D, Rodriguez-Torres M, Hassanein T, Gordon SC et al. Sofosbuvir for previously untreated chronic hepatitis C infection. N Engl J Med 2013; 368: 1878-1887.

25 Johnson SW, Davis MM, Stever LM, Priest DH. Curing the historically incurable: treatment success with ledipasvir/sofosbuvir for chronic hepatitis C virus in a heavily treatment-experienced individual. J Clin Pharm Ther 2016; 41: 727-729.

26 Obed A, Bashir A, Jarrad A. Rapid virological response after early treatment with a combined therapy of Ledipasvir and Sofosbuvir in HCV genotype 4 after living donor liver transplantation in a HCC Downstaged patient: case report and review of the literature. Am J Case Rep 2016; 17: 672-675.

27 Hutter G, Nowak D, Mossner M, Ganepola S, Mussig A, Allers K et al. Long-term control of HIV by CCR5 Delta32/Delta32 stem-cell transplantation. $N$ Engl J Med 2009; 360: 692-698.

28 Hutter G, Thiel E. Allogeneic transplantation of CCR5-deficient progenitor cells in a patient with HIV infection: an update after 3 years and the search for patient no. 2 . AIDS 2011; 25: 273-274.

29 Hofer U, Henley JE, Exline CM, Mulhern O, Lopez E, Cannon PM. Pre-clinical modeling of CCR5 knockout in human hematopoietic stem cells by zinc finger nucleases using humanized mice. J Infect Dis 2013; 208: S160-S164.

30 Cannon P, June C. Chemokine receptor 5 knockout strategies. Curr Opin HIV AIDS 2011; 6: 74-79.

31 Arbuthnot P. Gene Therapy for Viral Infections. Academic Press: MA, USA, 2015.

32 Ebina H, Misawa N, Kanemura Y, Koyanagi Y. Harnessing the CRISPR/Cas9 system to disrupt latent HIV-1 provirus. Sci Rep 2013; 3: 2510.

33 Hu W, Kaminski R, Yang F, Zhang Y, Cosentino L, Li F et al. RNA-directed gene editing specifically eradicates latent and prevents new HIV-1 infection. Proc Natl Acad Sci USA 2014; 111: 11461-11466.

34 Berkhout B, ter Brake O. Towards a durable RNAi gene therapy for HIV-AIDS. Expert Opin Biol Ther 2009; 9: 161-170.

35 Burnett JC, Zaia JA, Rossi JJ. Creating genetic resistance to HIV. Curr Opin Immunol 2012; 24: 625-632.

36 Grimm D, Streetz KL, Jopling CL, Storm TA, Pandey K, Davis CR et al. Fatality in mice due to oversaturation of cellular microRNA/short hairpin RNA pathways. Nature 2006; 441: 537-541.

37 Olejniczak M, Urbanek MO, Jaworska E, Witucki L, Szczesniak MW, Makalowska I et al. Sequence-non-specific effects generated by various types of RNA interference triggers. Biochim Biophys Acta 2016; 1859: 306-314.

38 Singh S, Narang AS, Mahato Rl. Subcellular fate and off-target effects of siRNA, shRNA, and miRNA. Pharm Res 2011; 28: 2996-3015.

39 Montuclard C, Hamza S, Rollot F, Evrard P, Faivre J, Hillon P et al. Causes of death in people with chronic HBV infection: a population-based cohort study. $J$ Hepatol 2015; 62: 1265-1271.

40 Yang N, Bertoletti A. Advances in therapeutics for chronic hepatitis B. Hepatol Int 2016; 10: 277-285.

41 Parvez MK, Arbab AH, Al-Dosari MS, Al-Rehaily AJ. Antiviral natural products against chronic hepatitis B: recent developments. Curr Pharm Des 2016; 22: 286-293.

42 Zeisel MB, Lucifora J, Mason WS, Sureau C, Beck J, Levrero M et al. Towards an HBV cure: state-of-the-art and unresolved questions-report of the ANRS workshop on HBV cure. Gut 2015; 64: 1314-1326.

43 Dever DP, Bak RO, Reinisch A, Camarena J, Washington G, Nicolas CE et al. CRISPR/ Cas9 beta-globin gene targeting in human haematopoietic stem cells. Nature 2016; 539: 384-389.
44 Ivacik D, Ely A, Arbuthnot P. Countering hepatitis B virus infection using RNAi: how far are we from the clinic? Rev Med Virol 2011; 21: 383-396.

45 Cradick TJ, Keck K, Bradshaw S, Jamieson AC, McCaffrey AP. Zinc-finger nucleases as a novel therapeutic strategy for targeting hepatitis B virus DNAs. Mol Ther 2010; 18: 947-954

46 Weber ND, Stone D, Sedlak RH, De Silva Feelixge HS, Roychoudhury P, Schiffer JT et al. AAV-mediated delivery of zinc finger nucleases targeting hepatitis B virus inhibits active replication. PloS One 2014; 9: e97579.

47 Zimmerman KA, Fischer KP, Joyce MA, Tyrrell DL. Zinc finger proteins designed to specifically target duck hepatitis B virus covalently closed circular DNA inhibit viral transcription in tissue culture. J Virol 2008; 82: 8013-8021.

48 Chen J, Zhang W, Lin J, Wang F, Wu M, Chen C et al. An efficient antiviral strategy for targeting hepatitis $\mathrm{B}$ virus genome using transcription activator-like effector nucleases. Mol Ther 2014; 22: 303-311.

49 Lin SR, Yang HC, Kuo YT, Liu CJ, Yang TY, Sung KC et al. The CRISPR/Cas9 system facilitates clearance of the intrahepatic HBV templates in vivo. Mol Ther Nucleic Acids 2014; 3: e186.

50 Zhen S, Hua L, Liu YH, Gao LC, Fu J, Wan DY et al. Harnessing the clustered regularly interspaced short palindromic repeat (CRISPR)/CRISPR-associated Cas9 system to disrupt the hepatitis B virus. Gene Ther 2015; 22: 404-412.

51 Wang J, Xu ZW, Liu S, Zhang RY, Ding SL, Xie XM et al. Dual gRNAs guided CRISPR/ Cas9 system inhibits hepatitis B virus replication. World J Gastroenterol 2015; 21: 9554-9565.

52 Seeger C, Sohn JA. Targeting hepatitis B virus With CRISPR/Cas9. Mol Ther 2014; 3: e216.

53 Morrissey DV, Blanchard K, Shaw L, Jensen K, Lockridge JA, Dickinson B et al. Activity of stabilized short interfering RNA in a mouse model of hepatitis $B$ virus replication. Hepatology 2005; 41: 1349-1356.

54 Morrissey DV, Lockridge JA, Shaw L, Blanchard K, Jensen K, Breen W et al. Potent and persistent in vivo anti-HBV activity of chemically modified siRNAs. Nat Biotechnol 2005; 23: 1002-1007.

55 Carmona S, Ely A, Crowther C, Moolla N, Salazar FH, Marion PL et al. Effective inhibition of HBV replication in vivo by anti-HBx short hairpin RNAs. Mol Ther 2006; 13: 411-421.

56 McCaffrey AP, Nakai H, Pandey K, Huang Z, Salazar FH, Xu H et al. Inhibition of hepatitis B virus in mice by RNA interference. Nat Biotechnol 2003; 21: 639-644.

57 Weinberg MS, Ely A, Barichievy S, Crowther C, Mufamadi S, Carmona S et al. Specific inhibition of HBV replication in vitro and in vivo with expressed long hairpin RNA. Mol Ther 2007; 15: 534-541.

58 Michler T, Grosse S, Mockenhaupt S, Roder N, Stuckler F, Knapp B et al. Blocking sense-strand activity improves potency, safety and specificity of anti-hepatitis $B$ virus short hairpin RNA. EMBO Mol Med 2016; 8: 1082-1098.

59 Gish RG, Yuen MF, Chan HL, Given BD, Lai CL, Locarnini SA et al. Synthetic RNAi triggers and their use in chronic hepatitis $B$ therapies with curative intent. Antiviral Res 2015; 121: 97-108.

60 Haasnoot J, de Vries W, Geutjes EJ, Prins M, de Haan P, Berkhout B. The Ebola virus VP35 protein is a suppressor of RNA silencing. PLoS Pathog 2007; 3: e86.

61 Geisbert TW, Lee AC, Robbins M, Geisbert JB, Honko AN, Sood V et al. Postexposure protection of non-human primates against a lethal Ebola virus challenge with RNA interference: a proof-of-concept study. Lancet 2010; 375: 1896-1905.

62 Ursic-Bedoya R, Mire CE, Robbins M, Geisbert JB, Judge A, MacLachlan I et al. Protection against lethal Marburg virus infection mediated by lipid encapsulated small interfering RNA. J Infect Dis 2014; 209: 562-570.

63 Thi EP, Mire CE, Ursic-Bedoya R, Geisbert JB, Lee AC, Agans KN et al. Marburg virus infection in nonhuman primates: therapeutic treatment by lipid-encapsulated siRNA. Sci Transl Med 2014; 6: 250ra116.

64 Scott T, Paweska JT, Arbuthnot P, Weinberg MS. Pathogenic effects of Rift Valley fever virus NSs gene are alleviated in cultured cells by expressed antiviral short hairpin RNAs. Antivir Ther 2012; 17: 643-656.

65 Snoy PJ. Establishing efficacy of human products using animals: the US food and drug administration's 'animal rule'. Vet Pathol 2010; 47: 774-778.

66 Kanapathipillai R, Henao Restrepo AM, Fast P, Wood D, Dye C, Kieny MP et al. Ebola vaccine--an urgent international priority. N Engl J Med 2014; 371: 2249-2251.

67 Beasley DW, Brasel TL, Comer JE. First vaccine approval under the FDA Animal Rule. NPJ Vaccines 2016; 1: 16013.

68 Abdulhaqq SA, Weiner DB. DNA vaccines: developing new strategies to enhance immune responses. Immunol Res 2008; 42: 219-232.

69 Davis HL, Mancini M, Michel ML, Whalen RG. DNA-mediated immunization to hepatitis B surface antigen: longevity of primary response and effect of boost. Vaccine 1996; 14: 910-915.

70 Mancini M, Davis $\mathrm{H}$, Tiollais $\mathrm{P}$, Michel ML. DNA-based immunization against the envelope proteins of the hepatitis B virus. J Biotechnol 1996; 44: 47-57. 
71 Mancini M, Hadchouel M, Tiollais P, Michel ML. Regulation of hepatitis B virus mRNA expression in a hepatitis $B$ surface antigen transgenic mouse model by IFNgamma-secreting T cells after DNA-based immunization. J Immunol 1998; 161: 5564-5570.

72 Buchbinder SP, Mehrotra DV, Duerr A, Fitzgerald DW, Mogg R, Li D et al. Efficacy assessment of a cell-mediated immunity HIV-1 vaccine (the Step Study): a doubleblind, randomised, placebo-controlled, test-of-concept trial. Lancet 2008; 372: 1881-1893.

73 Gray GE, Allen M, Moodie Z, Churchyard G, Bekker LG, Nchabeleng M et al. Safety and efficacy of the HVTN 503/Phambili study of a clade-B-based HIV-1 vaccine in South Africa: a double-blind, randomised, placebo-controlled test-of-concept phase 2b study. Lancet 2011; 11: 507-515.

74 Churchyard GJ, Morgan C, Adams E, Hural J, Graham BS, Moodie Z et al. A phase IIA randomized clinical trial of a multiclade HIV-1 DNA prime followed by a multiclade rAd5 HIV-1 vaccine boost in healthy adults (HVTN204). PloS One 2011; 6 : e21225.

75 Hammer SM, Sobieszczyk ME, Janes H, Karuna ST, Mulligan MJ, Grove D et al. Efficacy trial of a DNA/rAd5 HIV-1 preventive vaccine. N Engl J Med 2013; 369: 2083-2092.

76 Janes HE, Cohen KW, Frahm N, De Rosa SC, Sanchez B, Hural J et al. Higher T-cell responses induced by DNA/rAd5 HIV-1 preventive vaccine are associated with lower HIV-1 infection risk in an efficacy trial. J Infect Dis 2017; 215: 1376-1385.

77 Geisbert TW, Bailey M, Hensley L, Asiedu C, Geisbert J, Stanley D et al. Recombinant adenovirus serotype 26 (Ad26) and $\mathrm{Ad} 35$ vaccine vectors bypass immunity to Ad5 and protect nonhuman primates against ebolavirus challenge. J Virol 2011; 85: 4222-4233.

78 Baden LR, Walsh SR, Seaman MS, Tucker RP, Krause KH, Patel A et al. First-inhuman evaluation of the safety and immunogenicity of a recombinant adenovirus serotype 26 HIV-1 Env vaccine (IPCAVD 001). J Infect Dis 2013; 207: 240-247.

79 Barouch DH, Picker LJ. Novel vaccine vectors for HIV-1. Nat Rev Microbiol 2014; 12: 765-771.

80 Borducchi EN, Cabral C, Stephenson KE, Liu J, Abbink P, Ng'ang'a D et al. Ad26/ MVA therapeutic vaccination with TLR7 stimulation in SIV-infected rhesus monkeys. Nature 2016; 540: 284-287.

81 Balazs AB, Ouyang Y, Hong CM, Chen J, Nguyen SM, Rao DS et al. Vectored immunoprophylaxis protects humanized mice from mucosal HIV transmission. Nat Med 2014; 20: 296-300.

82 Hossain MA, Bungert J. Genome editing for sickle cell disease: a little BCL11A goes a long way. Mol Ther 2017; 25: 561-562.

83 Chang K-H, Smith SE, Sullivan T, Chen K, Zhou Q, West JA et al. Long-term engraftment and fetal globin induction upon BCL11A gene editing in bonemarrow-derived CD34+ hematopoietic stem and progenitor cells. Mol Ther 2017; 4: 137-148.

84 DeWitt MA, Magis W, Bray NL, Wang T, Berman JR, Urbinati F et al. Selection-free genome editing of the sickle mutation in human adult hematopoietic stem/ progenitor cells. Sci Transl Med 2016; 8: 360ra134.

85 Pepper MS, Gouveia C, Nőthling Slabbert M. Legislation governing pluripotent stem cells in South Africa. SAJBL 2015; 8: 23-31. 